\title{
Rho GTPases in A549 and Caco-2 cells dominating the endocytic pathways of nanocarbons with different morphologies
}

This article was published in the following Dove Press journal: International Journal of Nanomedicine

\author{
Siyang Song ${ }^{1,2, *}$ \\ Hongzhe $\mathrm{Fu}^{2, *}$ \\ Bing $\mathrm{He}^{2}$ \\ Dan Wang ${ }^{3}$ \\ Mengmeng Qin ${ }^{2}$ \\ Dan Yang ${ }^{1,2}$ \\ Dechun Liu ${ }^{2}$ \\ Ge Song ${ }^{2}$ \\ Yujie Shi ${ }^{2}$ \\ Hua Zhang ${ }^{2}$ \\ Xueqing Wang ${ }^{2}$ \\ Wenbing Dai \\ Qiang Zhang ${ }^{1,2}$
}

'School of Pharmacy, Shenyang Pharmaceutical University, Shenyang II0016, China; ${ }^{2}$ Beijing Key Laboratory of Molecular Pharmaceutics and the State Key Laboratory of Natural and Biomimetic Drugs, Peking University, Beijing I0019I, China; ${ }^{3}$ Pharmaceutics Department, Institute of Medicinal Biotechnology, Chinese Academy of Medical Science and Peking Union Medical College, Beijing I00050, China

*These authors contributed equally to this work

Correspondence: Wenbing Dai; Qiang Zhang

Pharmaceutics Department, Peking University Health Science Center, 38 Xueyuan Rd, Haidian District, Beijing, 100191, China

Email daiwb@bjmu.edu.cn; zqdodo@bjmu.edu.cn
Introduction: Endocytosis of nanomaterials is the first step of nano-bio interaction and current regulation is mostly by nanomaterials but seldom by intracellular signaling proteins.

Materials and methods: Herein, we synthesized tubular nanocarbon (oxMWCNT) and lamellar-like nanocarbon (oxGRAPHENE) and formulated their aqueous dispersion. A549 and Caco-2 cells were selected as the models of tumor and intestinal epithelial cells, respectively. After knocking down three members of Rho GTPases (Cdc42, Rac1, RhoA) in these two cell lines, their silencing effects on the uptake pathways of nanomaterials with different morphologies were investigated.

Results: An unexpected finding was that the knock-down led to opposite uptake trends in different types of cells. The endocytosis of carbon nanomaterials increased in Caco-2 cells when Rho GTPases were inactivated, while that in A549 cells decreased. For nanomaterials with different shapes, the involved GTPase member of Rho family, or regulating protein molecule, was different. Concretely, Cdc42 and Rac1 were involved in oxMWCNT endocytosis, while all three GTPases participated in oxGRAPHENE internalization. More interestingly, such difference induced different uptake pathways, namely, the cellular uptake of oxMWCNT was clathrin-mediated and oxGRAPHENE was caveolin-modulated, both with the involvement of dynamin.

Conclusion: In conclusion, this study provides new insights for the potential intervention in nano-bio interplay.

Keywords: shape, cellular uptake, intracellular distribution, nanomaterials, Rho GTPases

\section{Introduction}

In recent decades, nanomaterials or nanoscale systems, including polymer nanoparticles, lipid micelles, liposomes, dendrimers, carbon nanotubes (CNTs), graphene, quantum dots, AuNPs, and silica NPs, have been widely applied in imaging, regenerative medicine, medical devices, and theranostics, etc. ${ }^{1}$ Their endocytosis and intracellular trafficking of nanomaterials in targeted and normal cells, as is known, are of great importance for functioning and biological safety. For example, tumor-targeted nanoparticles are expected to preferentially be delivered to targeted cells and bypass the normal cells. After endocytosis, the nanoparticles interact with a specific intracellular target to exert the optimal therapeutic effect.

Generally, the endocytic processes of nanoparticles are divided into several phases. In the beginning, the nanoparticles approach and interact with cells specifically. Then, the plasma membrane invaginates specific membrane domains, engulfs the nanoparticles, and transforms into membrane-bound vesicles. After the vesicles are budding off from the membrane, the cargos are completely internalized. 
The physicochemical properties of nanoparticles, such as size, shape, surface charge, hydrophobicity, and surface modification, have been confirmed to have a great effect on their cellular uptake. ${ }^{2}$ For instance, nanoparticles with a larger aspect ratio were observed to be internalized at a faster rate and higher frequency. ${ }^{3,4}$ This indicates that cell internalization could be controlled via rational design and fabrication of nanoparticles with well-defined characteristics.

Besides, the biological function of cell structures also plays an essential role in cellular uptake, especially plasma membrane and cytoskeleton (microfilaments and microtubules), whose growth and maintenance are controlled by Rho GTPases, a class of kinases of eukaryotic cells. ${ }^{5}$ Rho GTPases have a profound impact on cell morphology, cell migration, vesicle transport, and other life activities, among which Rac1, RhoA, and Cdc42 are the most widely studied members. ${ }^{6-8}$

It has been reported that Rac1, RhoA, and $\mathrm{Cdc} 42$ are associated with actin reorganization, cell motility, cell-cell and cell-extracellular matrix adhesion as well as cell cycle progression, gene expression, and apoptosis. ${ }^{9}$ Rac1 is activated in protrusion and ruffling; RhoA's activity is related to protrusion, tail retraction, and ruffling; Cdc42 not only takes part in the process of protrusion, filopodia, but also controls invadopodia disassembly at the Golgi. ${ }^{10}$ However, the existing studies did not focus on the impact of these Rho GTPase members on cellular uptake of nanoparticles. This mechanism study provided foundation for subsequent research of specific regulation of nanoparticle endocytosis by Rho GTPases.

The purpose of this study was to investigate the effect of Rho GTPase members on the uptake of carbon nanomaterials with different shapes and their intracellular distribution in different cell lines. MWCNTs and GRAPHENE with evident different shapes were used as representative nanomaterials due to their wide application in drug delivery for tumor targeting and oral absorption enhancement. A549 and Caco-2 cells were selected as models of tumor and intestinal epithelial cells, respectively. The clarification of their impact on cellular uptake may provide a new intervention approach of cellular drug delivery and achieve higher efficacy and reduced side effects.

\section{Materials and methods \\ Materials}

MWCNTs were purchased from Daoking Co., Ltd (Beijing, China). GRAPHENE was provided by Qingdajiguang Co., Ltd (Beijing, China). The siRNA specifically targeting human $\mathrm{Cdc} 42$, Rac1, RhoA, and universal negative control
siRNA were purchased from RiboBio Co., Ltd. (Guangzhou, China). Rabbit monoclonal antibody of CDC42 (ab187643), mouse monoclonal antibody of Rac1 (ab33186), and rabbit monoclonal antibody of RhoA (ab187027) were purchased from Abcam (Cambridge, UK). Goat anti-rabbit secondary antibody, Alexa Fluor 647 (A32733), and goat anti-mouse IgG cross-adsorbed secondary antibody, were obtained from Thermo Fisher Scientific (Waltham, MA, USA). ZCL278 was purchased from Abmole Bioscience (Houston, TX, USA). NSC23766 and CCG1423 were purchased from Selleckchem (Houston, TX, USA). Antibodies for GAPHD, HRP-labeled secondary antibodies, and LDH Cytotoxicity Assay Kit were purchased from Beyotime Biotechnology (Shanghai, China). Rhodamine-phalloidin and Hoechst 33342 were obtained from Molecular Probes (Eugene, OR, USA). Lyso-tracker and Mito-tracker were purchased from Thermo Fisher Scientific. Dynasore, filipin, genistein, cytochalasin D, chlorpromazine, and EIPA were all provided by Sigma-Aldrich Co. (St Louis, MO, USA). Opti-MEM, lipofectamine ${ }^{\circledR} 3000$, and Lipofectamine ${ }^{\circledR}$ RNAiMax were all purchased from Thermo Fisher Scientific. RNA extraction kit was purchased from Thermo Fisher Scientific. Other chemical reagents used in this study were of analytical grade.

A549 cell line was purchased from American Type Culture Collection (Manassas, VA, USA) and Caco-2 cell line was obtained from China Center for Type Culture Collection (Wuhan, China). RPMI-1640 medium, MEM, and penicillin-streptomycin were obtained from Macgene Biotechnology Ltd. (Beijing, China). Gibco ${ }^{\circledR}$ fetal bovine serum was purchased from Thermo Fisher Scientific.

\section{Synthesis of oxidized MWCNTs}

OxMWCNTs were synthesized with concentrated nitric acid as described previously. ${ }^{11}$ Briefly, $30 \mathrm{mg}$ MWCNTs and $6 \mathrm{~mL}$ concentrated nitric acid (65\%) were mixed in a roundbottom flask. Then, the mixture was refluxed at $83^{\circ} \mathrm{C}$ with a condenser under magnetic stirring for $48 \mathrm{~h}$. Solid products were collected by centrifugation and washed up to neutral $\mathrm{pH}$ and vacuum dried for $24 \mathrm{~h}$.

\section{Synthesis of oxidized GRAPHENE}

OxGRAPHENE was synthesized using a modified Hummers method. ${ }^{12}$ In brief, $100 \mathrm{mg}$ graphene and $50 \mathrm{mg} \mathrm{NaNO}_{3}$ were dispersed in $2.4 \mathrm{~mL} \mathrm{H}_{2} \mathrm{SO}_{4}$ in a $10 \mathrm{~mL}$ round-bottom flask, stirring for $30 \mathrm{~min}$ in an ice bath. Then, $300 \mathrm{mg} \mathrm{\textrm {KMnSO } _ { 4 }}$ was added slowly to the mixture under vigorous stirring. After that, the ice bath was removed, and the mixture was stirred at room temperature overnight. Then, $3 \mathrm{~mL} \mathrm{H}_{2} \mathrm{O}$ was added dropwise while maintaining vigorous stirring and 
the mixture was then refluxed at $98^{\circ} \mathrm{C}$ for $24 \mathrm{~h}$. After $1 \mathrm{~mL}$ $\mathrm{H}_{2} \mathrm{O}_{2}$ was mixed in with the suspension, the precipitation was collected by filtration and purified by washing with $5 \%$ $\mathrm{HCl}$. Finally, the product was washed up to neutral $\mathrm{pH}$ and vacuum dried for $24 \mathrm{~h}$.

\section{Preparation of oxMWCNTs or oxGRAPHENE dispersions}

Dispersion of oxMWCNTs or oxGRAPHENE was prepared using ultrasonic dispersion method. The dry powder of oxMWCNTs or oxGRAPHENE was dispersed in cell culture medium containing $1 \%$ BSA. Then, the mixture was dispersed by sonication at $200 \mathrm{~W}$ for $10 \mathrm{~min}$.

\section{Characterization of oxMWCNTs, oxGRAPHENE, and their dispersions}

Fourier transform infrared (FTIR) spectroscopy and Raman spectroscopy were performed as described previously, and a direct acid-base titration analysis was implemented to determine the concentration of carboxyl groups. ${ }^{13,14} \mathrm{Q} 50$ thermogravimetric analyzer was utilized to perform thermogravimetric analysis (TGA) under nitrogen atmosphere with a ratio of $10^{\circ} \mathrm{C} / \mathrm{min}$ in a temperature range from $25^{\circ} \mathrm{C}$ to $900^{\circ} \mathrm{C}$. Inductively coupled plasma mass spectrometry was applied to quantify the metal impurities. The size of oxMWCNTs and oxGRAPHENE in medium dispersion were evaluated by dynamic light scattering (DLS) analysis using the Malvern Zetasizer Nano ZS (Malvern Instruments, Malvern, UK) at $25^{\circ} \mathrm{C}$. Transmission electron microscopy (TEM) (JEM 1200EX; JEOL, Tokyo, Japan) was also applied to observe the morphology of the carbon nanomaterials. A dispersion containing $25 \mu \mathrm{g} / \mathrm{mL}$ oxMWCNTs or oxGRAPHENE was dropped on a copper grid. The sample was observed after air drying.

\section{RNA interference in A549/Caco-2 cell lines}

A549/Caco-2 cells were transfected with siRNA specifically targeting human $\mathrm{Cdc} 42$ gene, Racl gene or RhoA gene with Lipofectamine ${ }^{\circledR}$ RNAiMAX (for A549 cells) or Lipofectamine $^{\circledR} 3000$ (for Caco-2 cells) according to the manufacturer's instructions. Total RNA was extracted for qPCR determination $48 \mathrm{~h}$ after transfection. This protocol was based on SYBR Green detection system. Primers were used at $10 \mathrm{pM}$ each. The mix included $10 \mu \mathrm{L}$ of SYBR Green qPCR Mix, $0.4 \mu \mathrm{L}$ of each primer, $8.2 \mu \mathrm{L}$ of sterile PCR grade water, and $1 \mu \mathrm{L}$ of template cDNA was added in a final volume of $20 \mu \mathrm{L}$. Samples were amplified as follows: an initial denaturation step at $95^{\circ} \mathrm{C}$ for $2 \mathrm{~min}$, followed by 40 cycles at $95^{\circ} \mathrm{C}$ for $15 \mathrm{sec}$ (denaturation), $60^{\circ} \mathrm{C}$ for $1 \mathrm{~min}$ (annealing and elongation). After amplification, melting curve analyses were performed to differentiate the knockdown efficiency.

\section{Expression of related Rho GTPases in A549/Caco-2 cell lines}

Western blot and immunofluorescence assay were applied to confirm the expression of related Rho GTPases (Cdc42, Rac1, and RhoA). Western blot was performed as described previously. ${ }^{15}$ Cells were seeded in dishes for immunofluorescence assay. After fixation with 4\% paraformaldehyde, cells were permeated with TPBS (PBS $+0.1 \%$ Triton X-100) and blocked with 5\% BSA solution. After incubation with antibodies, the cell nuclei were stained with Hoechst $33342(5 \mu \mathrm{g} / \mathrm{mL})$ and the expression of Cdc42, Rac1, and RhoA was observed using confocal laser scanning microscopy (CLSM).

\section{Cytotoxicity study of oxMWCNTs, oxGRAPHENE, and inhibitors}

The LDH assay was performed to study the cytotoxicity of the nanodispersion of oxMWCNTs, oxGRAPHENE, and specific inhibitors of Rho GTPases. Cells were seeded in a 96-well plate and dispersions of carbon nanomaterials or specific inhibitors of Rho GTPases of various concentrations were added to the plate. After incubation for $24 \mathrm{~h}$, the LDH release was detected by LDH Cytotoxicity Assay Kit following the manufacturer's protocol.

\section{Investigation of cellular uptake}

Cellular uptake of carbon nanomaterials was observed by CLSM and quantified by calculating fluorescence intensity. Cells were seeded in dishes for CLSM at a density of $3 \times 10^{4}$ cells $/ \mathrm{mL}$. After fixation with 4\% paraformaldehyde, the dispersion of oxMWCNTs or oxGRAPHENE was added to the plate and incubated for $24 \mathrm{~h}$. F-actin and nuclei were marked with rhodamine-phalloidin (diluted in 1\% BSA solution) and Hoechst 33342. The carbon nanomaterials were detected by reflected signals through fluorescent channels as reported, and the amount of carbon nanomaterials was determined by calculating intensity of certain signals using the Columbus system. ${ }^{16}$

\section{Inhibition of cellular uptake} Internalization pathway studies of oxMWCNTs or oxGRAPHENE

After cells were seeded in 24-well plates, various inhibitors of endocytic pathways (listed in Table 1) were added and the plate was incubated at $37^{\circ} \mathrm{C}$ for $0.5 \mathrm{~h}$. The medium was then removed, and carbon nanomaterials were added 
Table I Inhibitors used in the study of cell uptake mechanism

\begin{tabular}{lll}
\hline Inhibitors & Concentration & Function \\
\hline Dynasore & $80 \mu \mathrm{g} / \mathrm{mL}$ & $\begin{array}{l}\text { Inhibitor of dynamin, } \\
\text { blocking clathrin, and lipid } \\
\text { raft/caveolae-mediated } \\
\text { endocytosis }\end{array}$ \\
Filipin & $0.5 \mu \mathrm{g} / \mathrm{mL}$ & $\begin{array}{l}\text { Inhibitor of lipid raft/caveolae- } \\
\text { mediated endocytosis by } \\
\text { depleting cholesterol }\end{array}$ \\
Genistein & $100 \mu \mathrm{M}$ & $\begin{array}{l}\text { Inhibitor of protein tyrosine } \\
\text { kinase and caveolin- }{ }^{19}\end{array}$ \\
Chlorpromazine & $50 \mu \mathrm{M}$ & $\begin{array}{l}\text { Inhibitor of clathrin-mediated } \\
\text { endocytosis }\end{array}$ \\
Cytochalasin D & $500 \mathrm{nM}$ & $\begin{array}{l}\text { Stimulating actin } \\
\text { depolymerization and } \\
\text { inhibiting potent actin } \\
\text { polymerization }\end{array}$ \\
& & $\begin{array}{l}\text { Inhibitor of macrocytosis by } \\
\text { blocking } \mathrm{Na}^{+} / \mathrm{H}^{+} \text {ion channel }\end{array}$
\end{tabular}

and incubated with cells for $24 \mathrm{~h}$. The following steps were the same as described in the investigation of cellular uptake section.

\section{TEM observation}

Cells were seeded in a 6 -well plate with a density of $1.5 \times 10^{5}$ cells per well in $2 \mathrm{~mL}$ cell culture medium and incubated in $5 \% \mathrm{CO}_{2}$ at $37^{\circ} \mathrm{C}$ for $12 \mathrm{~h}$. The dispersion of carbon nanomaterials was added to the plate and incubated with cells for $24 \mathrm{~h}$. Then, the cells were collected and fixed with $2.5 \%$ glutaraldehyde solution for $12 \mathrm{~h}$ and with osmium oxide for $2 \mathrm{~h}$ at $4^{\circ} \mathrm{C}$. After dehydration with acetone, the cells were embedded in the epoxy resin, cut into thin slices, and dropped on a copper grid. The samples were observed with transmission electron microscope JEM1230 (JEOL).

\section{CLSM study}

Cells were seeded in dishes for CLSM at a density of $3 \times 10^{4}$ cells per dish in $1 \mathrm{~mL}$ cell culture medium and incubated in $5 \% \mathrm{CO}_{2}$ at $37^{\circ} \mathrm{C}$ for $24 \mathrm{~h}$. Then, the cells were incubated with $25 \mu \mathrm{g} / \mathrm{mL}$ carbon nanomaterials for $24 \mathrm{~h}$. After that, the distribution of carbon nanomaterials in various organelles was observed by confocal laser scanning microscope TCS SP8 (Leica Microsystems, Wetzlar, Germany).

\section{Statistical analysis}

All experiments were performed in triplicate. Data were expressed as mean \pm SD or SE and analyzed by ordinary one-way/two-way ANOVA, tested by Sidak's multiple comparisons test.

\section{Results and discussion Synthesis and characterization of oxidized MWCNTs and GRAPHENE}

Both MWCNTs and GRAPHENE are hydrophobic materials. Thus, hydrophilic groups, such as carboxyl group, were induced to the surface to achieve their stable dispersion in the water phase. ${ }^{23}$ The characterization (FTIR spectrum, Raman spectrum, TGA curve, concentration of carboxyl group, content of metal impurities of MWCNTs and GRAPHENE before or after oxidation) of the nanomaterials was showed in Figure 1.

The hydrodynamic diameter of the nanoparticles was $\sim 200 \mathrm{~nm}$ and could remain stable for $24 \mathrm{~h}$ (Figure 2A). As shown in Figure 2C, the TEM images exhibited that oxMWCNTs dispersed in cell culture medium were rod-like, while oxGRAPHENE was lamellar in shape.

It was observed that nanoparticles of oxMWCNTs and oxGRAPHENE were $\sim 200 \mathrm{~nm}$, which was consistent with the results of DLS. Besides, the tendency of gather decreased after oxidation and ultrasonic dispersion owing to the hydrophilicity and electrostatic stability that functional groups such as carboxyl groups have brought into the system.

The LDH assay showed that the dispersions of oxMWCNTs and oxGRAPHENE did not show significant cytotoxicity in A549 and Caco-2 cell lines with the concentration up to $100 \mu \mathrm{g} / \mathrm{mL}$ (Figure 3), indicating the two nanomaterials could be used as models in the following mechanism study. A concentration of $25 \mu \mathrm{g} / \mathrm{mL}$ was chosen for the following experiments.

\section{Expression of related Rho GTPases in A549/Caco-2 cell lines}

To confirm the influence of Rho GTPases on nanomaterials, the expression and the knock-down efficiency were first confirmed. The regulated expression of the three Rho GTPase members was achieved by RNA interference. Knock-down efficiency on the two cell lines was analyzed by qPCR, Western blot, and immunofluorescence (Figure 4). The maximum knock-down efficiency mRNA was selected for subsequent experiments. The mRNA level of Cdc42, Rac1, and RhoA decreased more than $90 \%$ and $60 \%$ in A549 cells and in Caco- 2 cells, respectively. Results of Western blot and immunofluorescence were consistent with that of the qPCR study.

\section{The impact of Rho GTPases on cellular uptake in A549 cell line}

The endocytosis of oxMWCNTs in A549 cells with/without Rho GTPases knock-down is shown in Figure 5. Quantification 
A
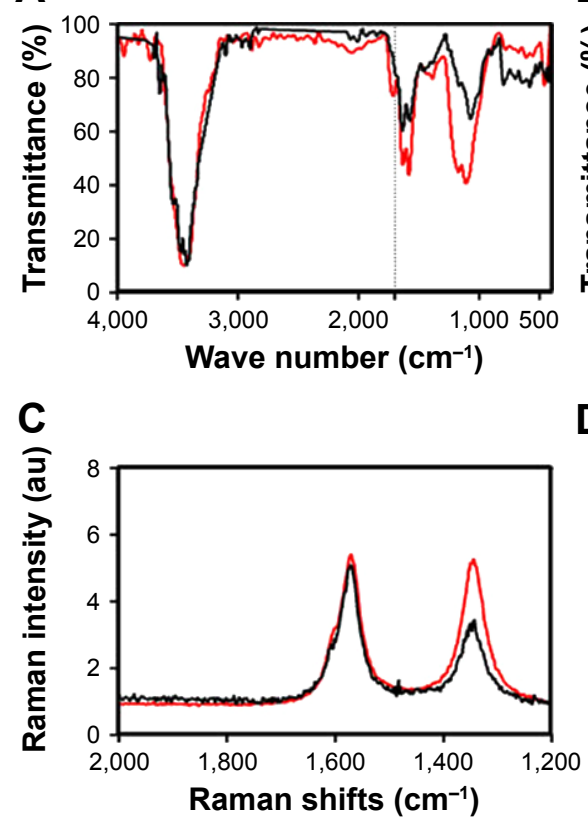

E

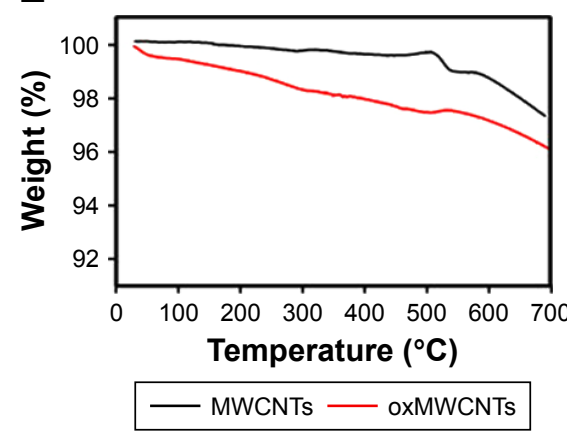

B

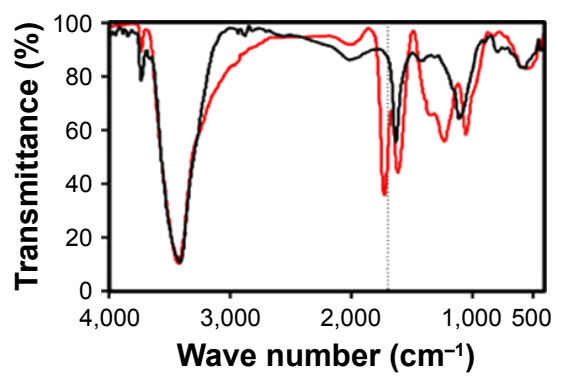

D

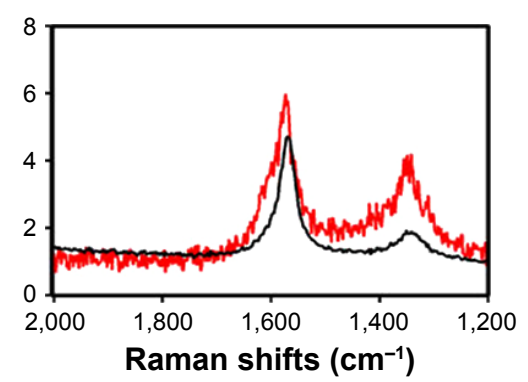

$\mathbf{F}$

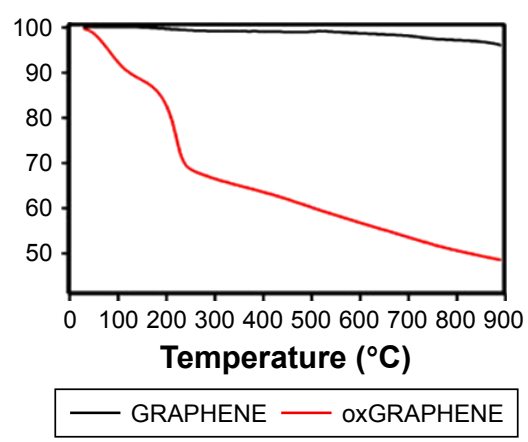

G

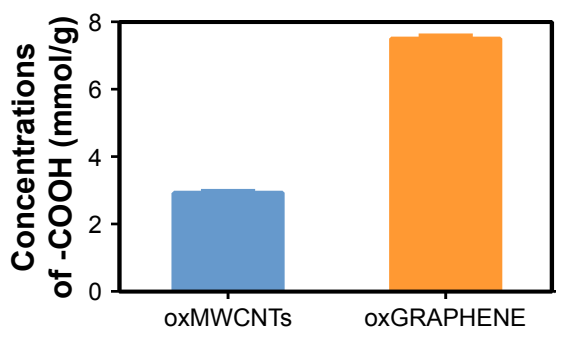

H

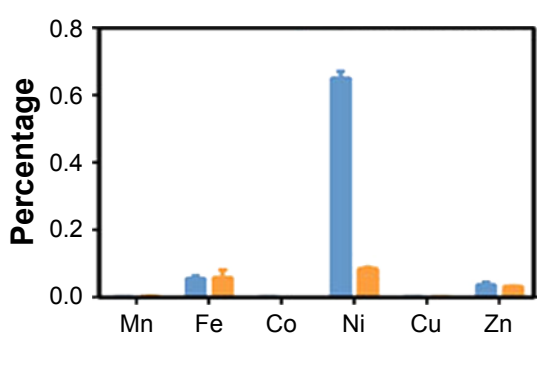

I

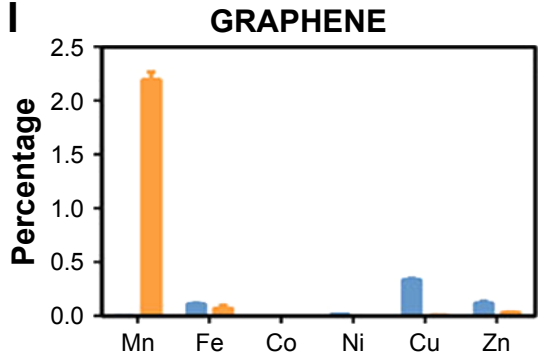

Before oxidation $\quad$ After oxidation

Figure I FTIR spectra (A and B), Raman spectra (C and D), TGA curves (E and F), concentration of carboxyl group (G), and content of metal impurities (H and I) of MWCNTs and GRAPHENE before and after oxidation.

Abbreviations: FTIR, Fourier transform infrared; TGA, thermogravimetric analysis; MWCNTs, multi-walled carbon nanotubes.

of oxMWCNTs fluorescence revealed that the three Rho GTPases influenced the cellular uptake of oxMWCNTs to different degrees (Figure 5B). Absence of $\mathrm{Cdc} 42$ led to a significant reduction of oxMWCNTs internalization, while no difference was observed when Rac1 or RhoA gene was silenced. Specific inhibitors of Cdc42 (ZCL278), Rac1 (NSC23766), and RhoA (CCG1423) were also used for further exploration. The results were consistent with those of RNA interference (Figure 5E and F). These findings indicated that $\mathrm{Cdc} 42$ played a vital role in the uptake of oxMWCNTs in A549 cells, while Rac1 and RhoA might not be involved in this process. The effect of the three Rho GTPases on cellular uptake of lamellar oxGRAPHENE was also investigated. It was found that down-regulation of expression (Figure $5 \mathrm{C}$ and $\mathrm{D}$ ) or blocking by inhibitors (Figure 5G and $\mathrm{H}$ ) of Rho GTPases had an identical decrease trend in cellular uptake of oxGRAPHENE, suggesting that $\mathrm{Cdc} 42$, Rac1, and RhoA participated in the endocytosis of oxGRAPHENE in A549 cells.

Apart from obvious differences in shape, oxMWCNTs and oxGRAPHENE, the two carbon nanomaterials, have similar physicochemical properties and components, plasticity, size, and charge (Figure 2). While all three of the Rho GTPases influenced the cellular uptake of the lamellar nanomaterial (oxGRAPHENE), only Cdc42 was involved in that of the rod-like oxMWCNTs. It is considered that nanoparticles with a larger aspect ratio were internalized at a higher speed and frequency and oxGRAPHENE, as a slim lamellar nanomaterial, might have a larger aspect rate which needed more Rho GTPases to participate and transfer it. Therefore, in the process of cellular uptake of nanomaterials with different shapes, the involved GTPase member of Rho family may be different. ${ }^{3}$ 
A
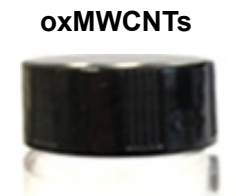

$\stackrel{5}{\circ}$

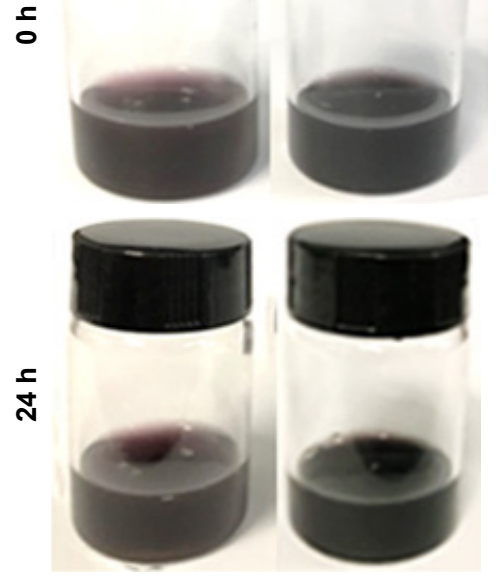

C
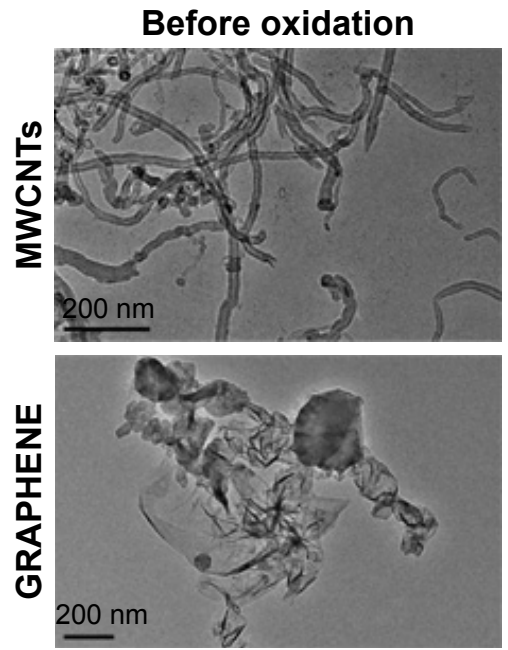

B
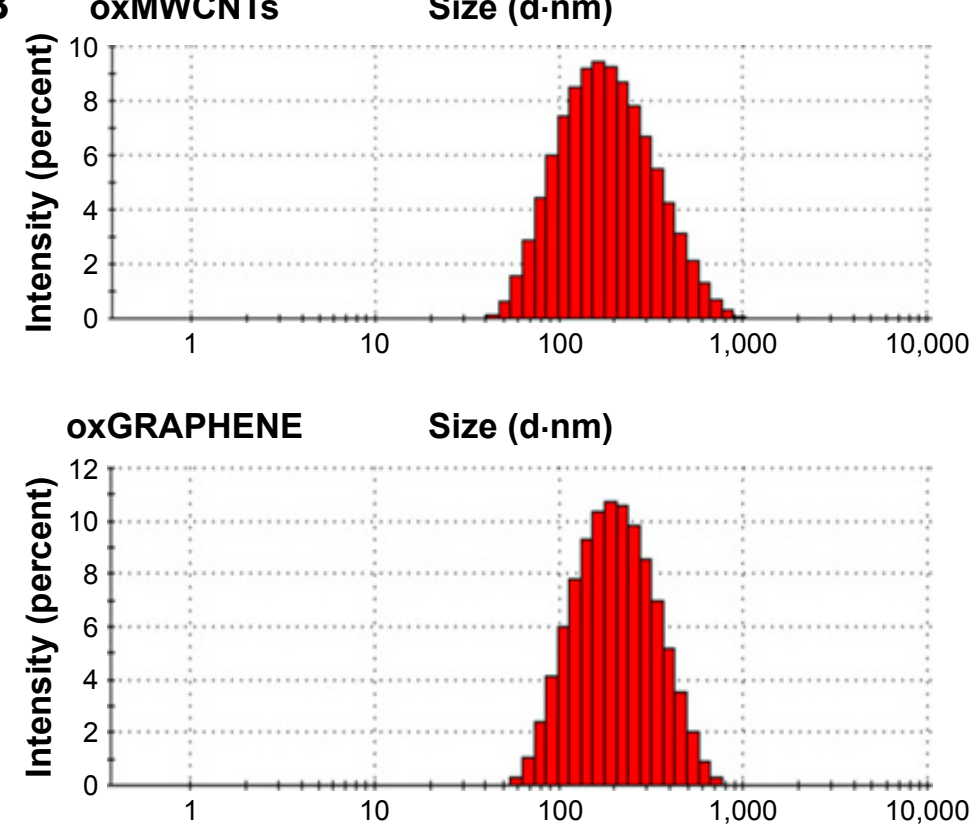

After oxidation

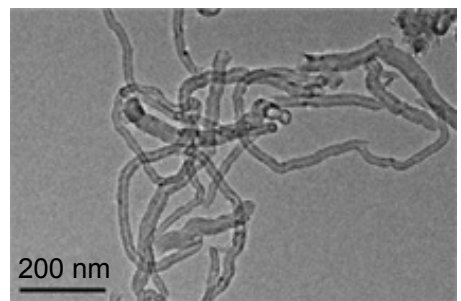

Nanoparticle suspension

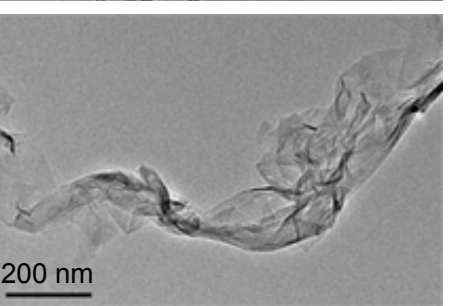

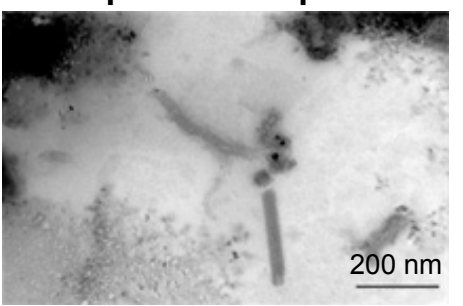

$200 \mathrm{~nm}$

Figure 2 Appearance of oxMWCNT and oxGRAPHENE dispersions $(25 \mu \mathrm{g} / \mathrm{mL})(\mathbf{A})$. (B) Size distribution of the nanocarbon dispersion. (C) TEM images of MWCNTs and GRAPHENE before and after oxidation. The nanoparticle suspension after ultrasonic dispersion of oxMWCNTs and oxGRAPHENE was also indicated in the last line. Abbreviations: MWCNTs, multi-walled carbon nanotubes; TEM, transmission electron microscopy.

\section{The impact of Rho GTPases on cellular uptake in Caco-2 cell line}

Nevertheless, the two nanomaterials demonstrated different endocytic behavior in Caco-2 cells as opposed to A549 cells (Figure 6). As shown in Figure 6A and B, with down-regulation of expression of $\mathrm{Cdc} 42$ and Rac1, the internalization amount of oxMWCNTs in Caco-2 cells increased significantly. The trend was consistent with this result when $\mathrm{Cdc} 42$ was blocked by inhibitors (Figure 6E and F). However, RhoA seemed not to influence the cellular uptake of oxMWCNTs. As for oxGRAPHENE, its uptake behavior in Caco-2 cells was similar to that of oxMWCNTs, which was regulated by Cde42 and Rac1 but not by RhoA (Figure 6C and D).
It was surprising that the uptake of carbon nanomaterials increased in Caco-2 cells when Rho GTPases were knocked down or inactivated, which was opposite to that in A549 cells. The explanation for this phenomenon might be that the tight junctions of Caco-2 cells were subjected to Rho GTPases' regulation; specifically, the reorganization of cytoskeleton was regulated by Rho GTPases, which eventually influenced the cell permeability. ${ }^{24}$ However, it is reported that Rho GTPase members play different roles in this process. RhoA activation disrupts junctions, leading to leaky barrier, whereas activation of $\mathrm{Rac} 1$ and $\mathrm{Cdc} 42$ promotes junctional assembly. ${ }^{25}$ In our work, a tight junction still existed in Caco-2 cells despite not being cultured as monolayers in 

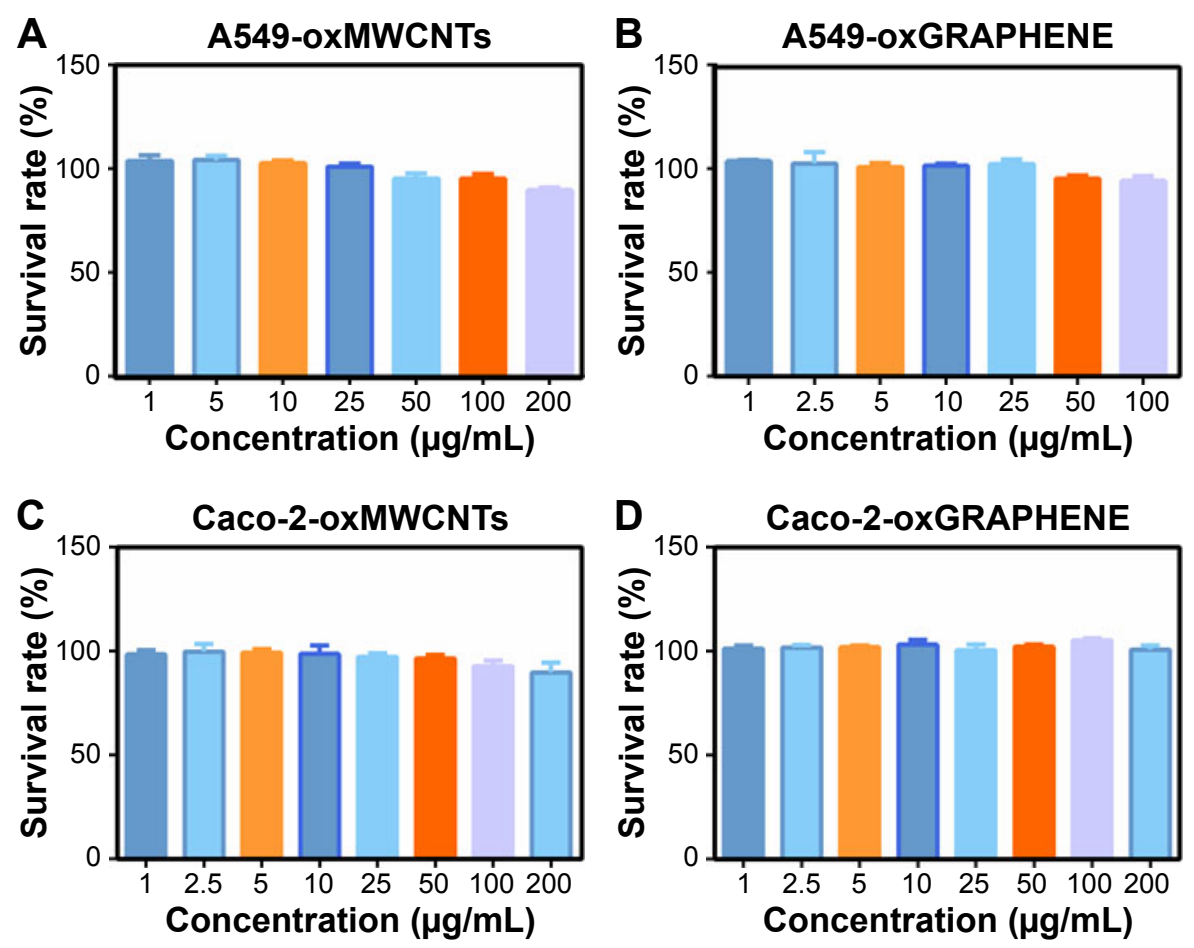

Figure 3 The viability of A549 cells and Caco-2 cells treated with oxMWCNTs or oxGRAPHENE. According to the LDH assay the dispersion of oxMWCNTs and oxGRAPHENE showed no significant cytotoxicity in A549 cell line and Caco-2 cell line when the concentration was below $100 \mu \mathrm{g} / \mathrm{mL}$.

Note: (A, B) The viability of A549 cells with oxMWCNTs and oxGRAPHENE. (C, D) The viability of Caco-2 cells with oxMWCNTs and oxGRAPHENE.

Abbreviation: MWCNTs, multi-walled carbon nanotubes.

A
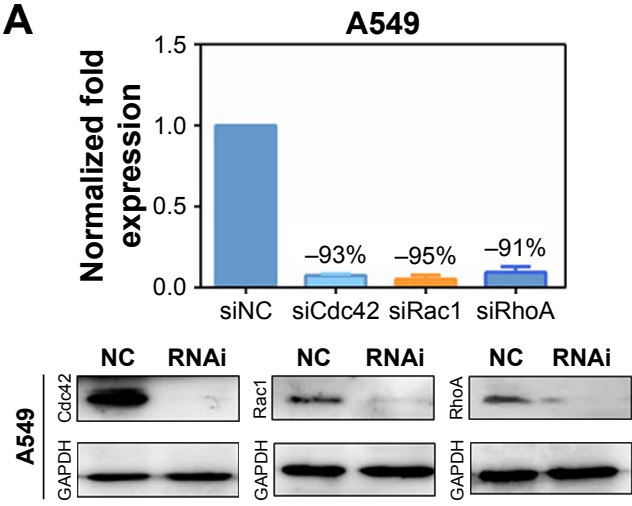

B
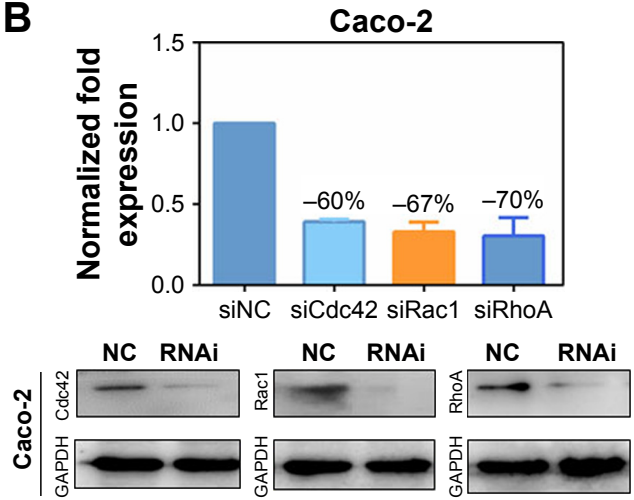

C
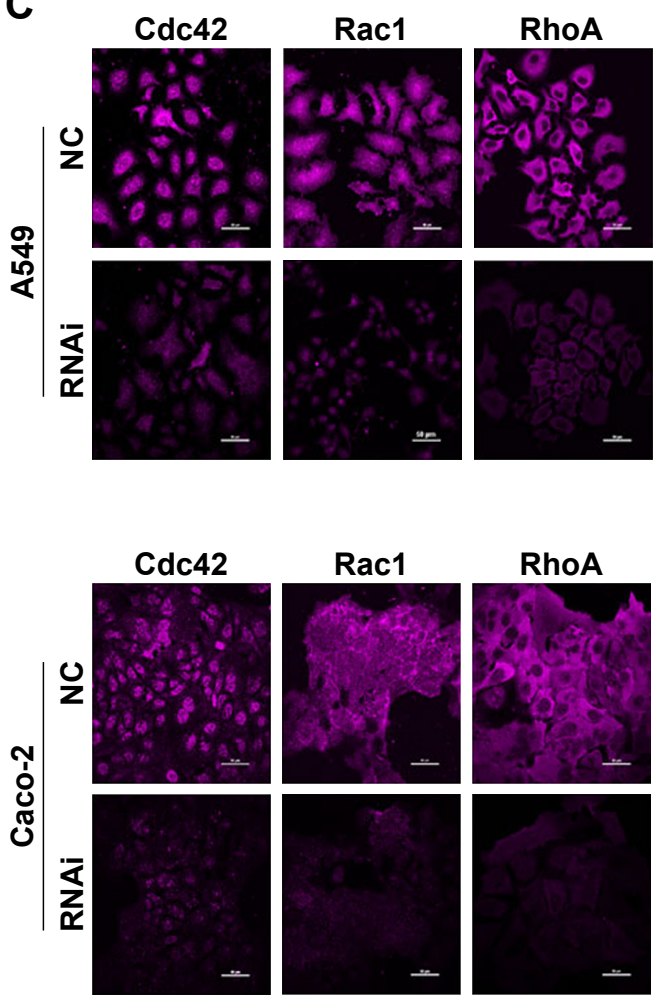

Figure 4 The qPCR and Western blot analysis of Cdc42, Racl, and RhoA in A549 cells (A) and Caco-2 cells (B). Immunofluorescence analyses of the expression of Cdc42, Racl, and RhoA in A549 cells and Caco-2 cells (C). Scale bar $=50 \mu \mathrm{m}$.

Abbreviation: NC, negative control. 
transwell plates, while A549 cells did not (Figures 5A, C Mechanism of cellular uptake of and 6A, C). Thus, once knocked down, Rac1 and Cdc42 might lead to increased permeability while RhoA did not demonstrate this effect.

\section{oxMWCNTs and oxGRAPHENE}

To further explore the mechanism of cellular uptake of oxMWCNTs and oxGRAPHENE, specific inhibitors including
A
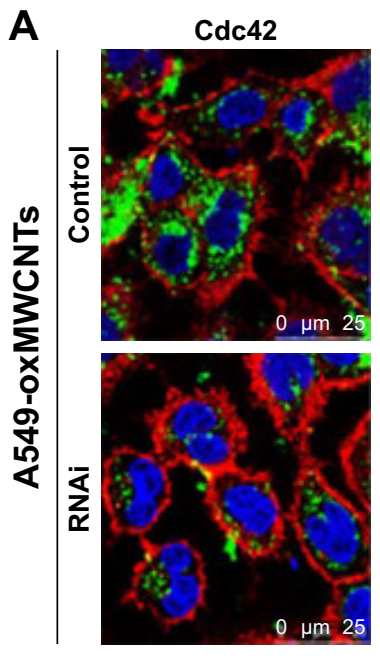

C

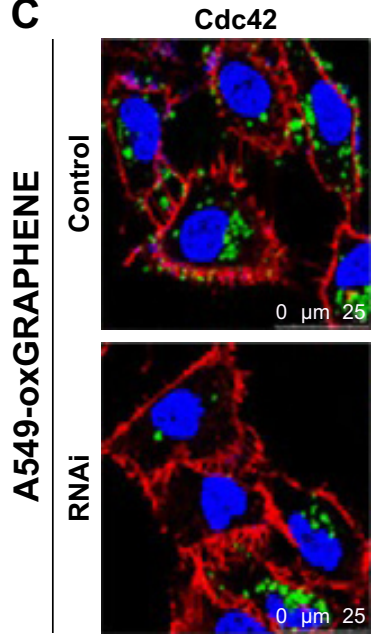

Rac1
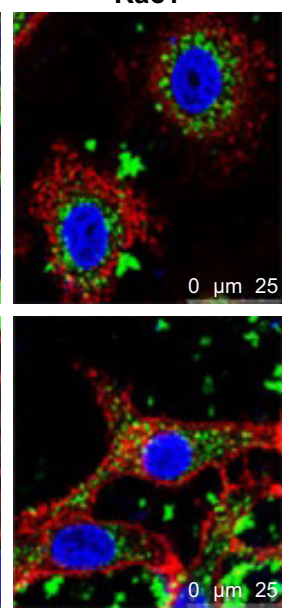

Rac1

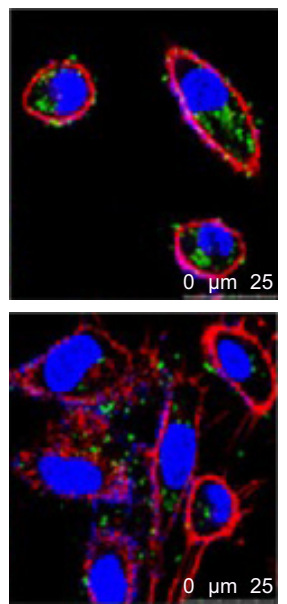

RhoA
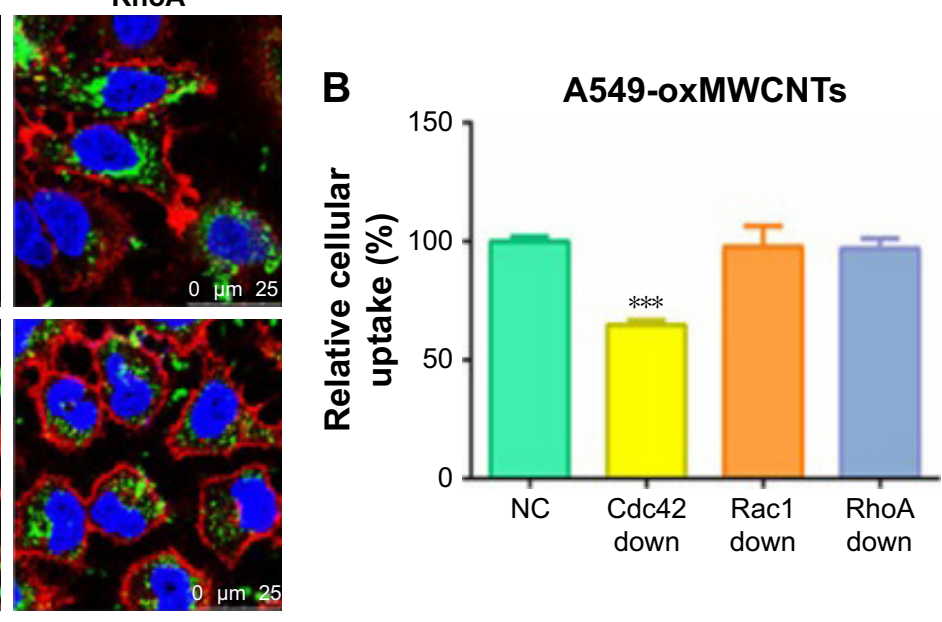

RhoA
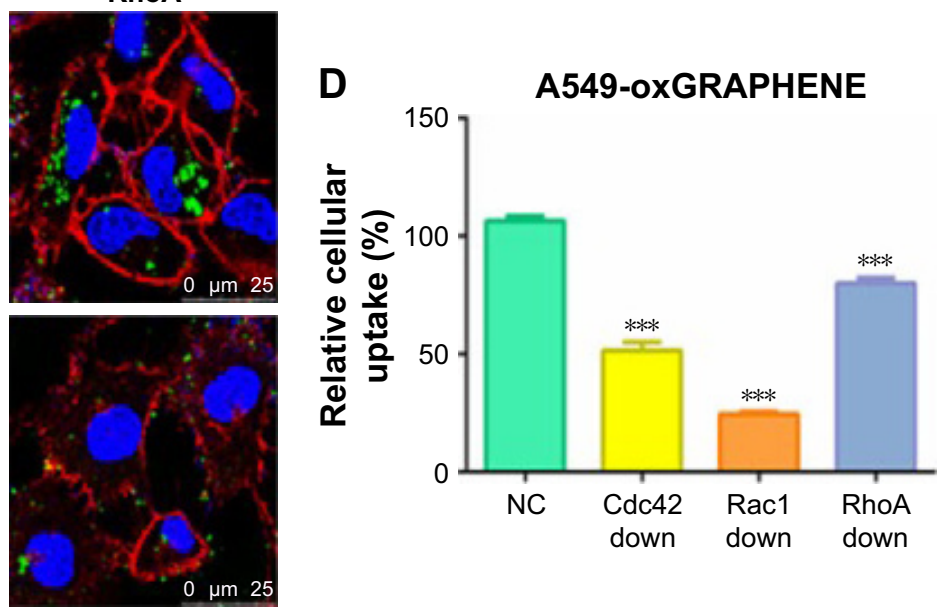

E

A549-oxMWCNTs
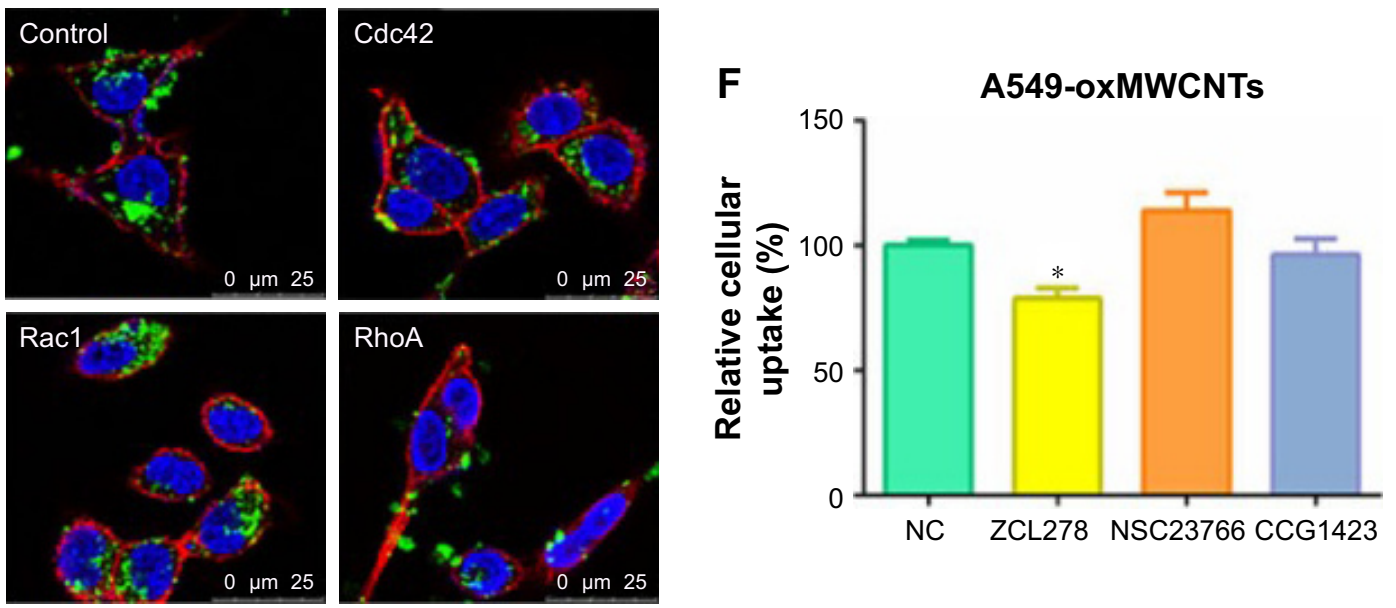

Figure 5 (Continued) 
G
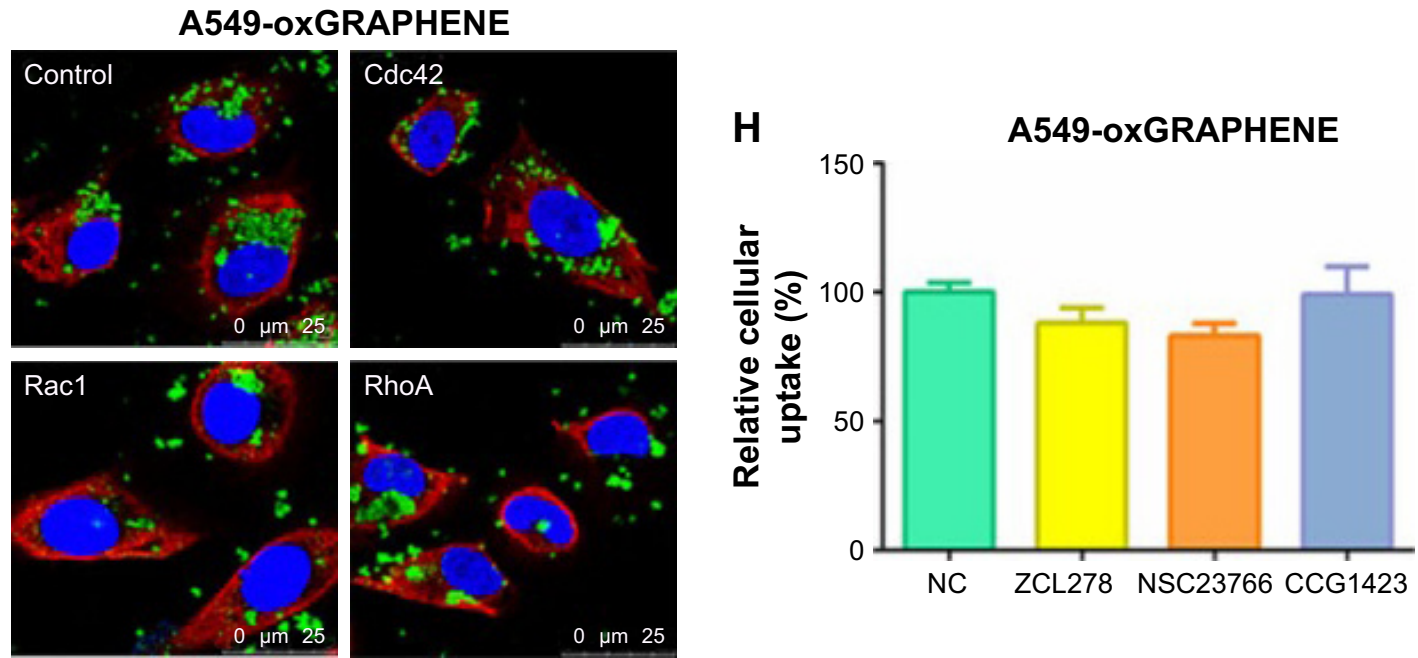

Figure 5 The endocytosis of oxMWCNTs and oxGRAPHENE in A549 cells after down-regulation of Cdc42, Racl, and RhoA. The carbon nanomaterials (green) were detected by reflected signals. (A-D) CLSM images of endocytosis and relative cellular uptake of oxMWCNTs or oxGRAPHENE in wild and Rho GTPase-silenced A549 cells. $(\mathbf{E}-\mathbf{H})$ The endocytosis of oxMWCNTs and oxGRAPHENE in A549 cells after inactivation of Cdc42, Racl, and RhoA. Data were expressed as mean \pm SE, $n$ (indicates different cells) $\geq 30(* P<0.05 ; * * * P<0.001)$.

Abbreviations: MWCNTs, multi-walled carbon nanotubes; CLSM, confocal laser scanning microscopy; NC, negative control.

A

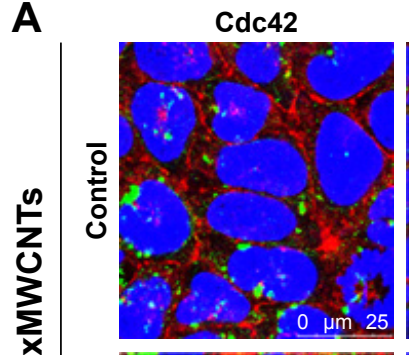

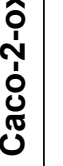

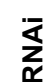

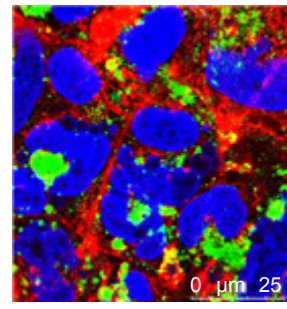

C
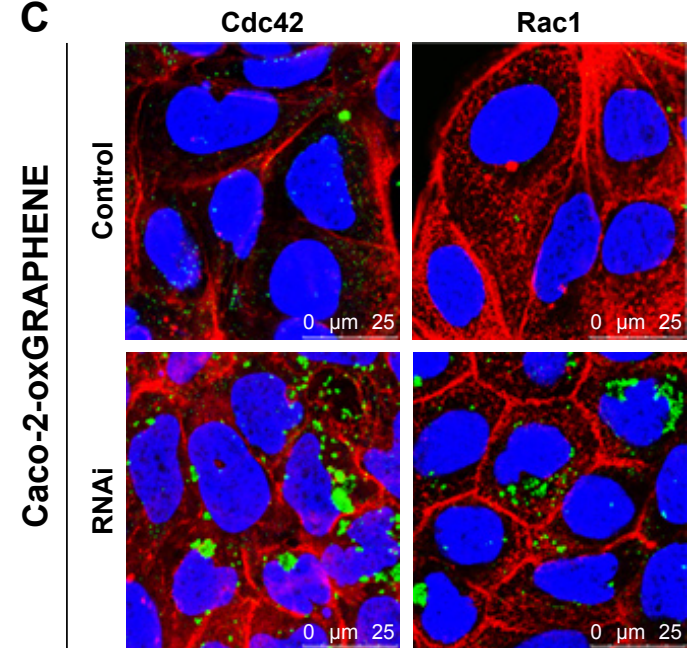

Rac1
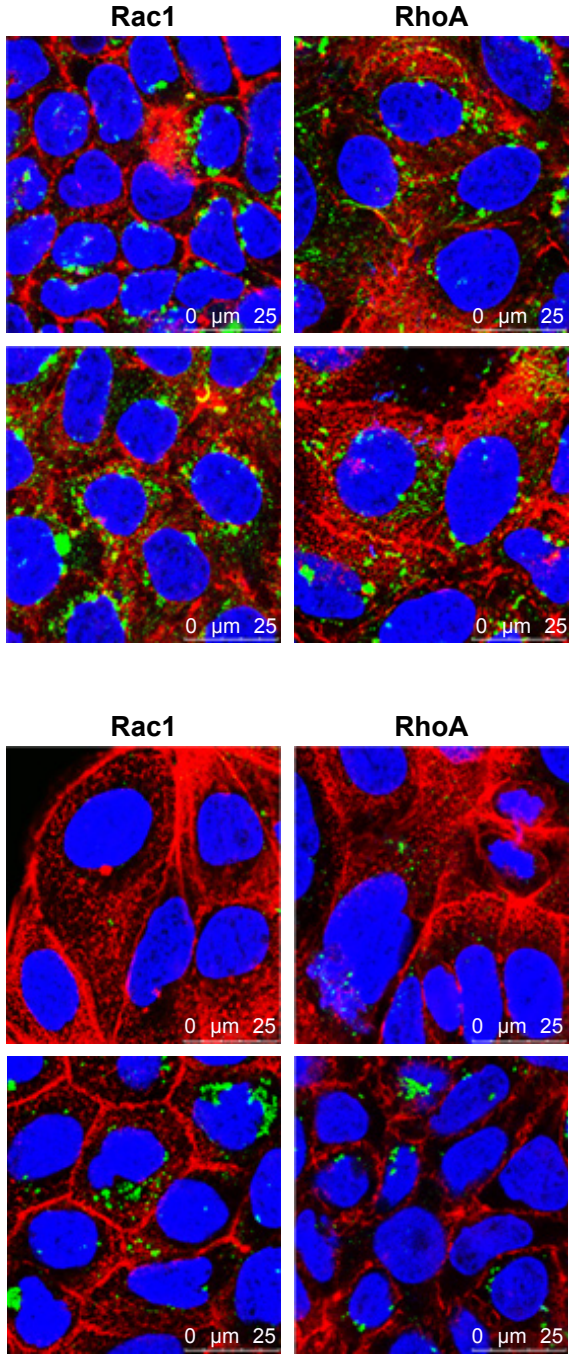

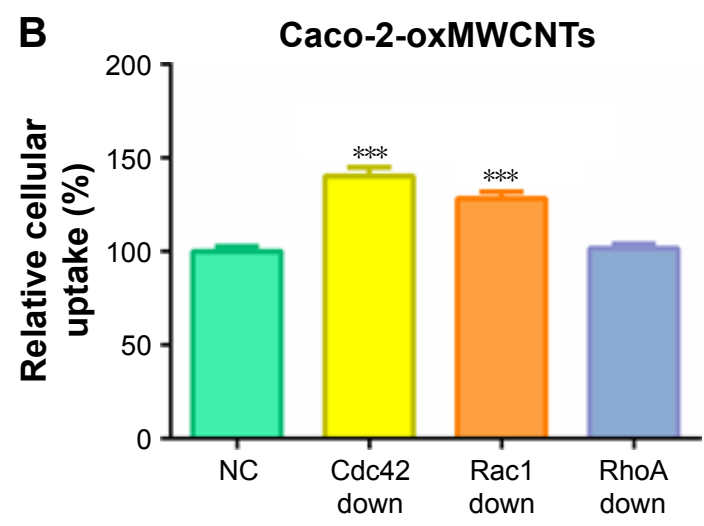

D Caco-2-oxGRAPHENE

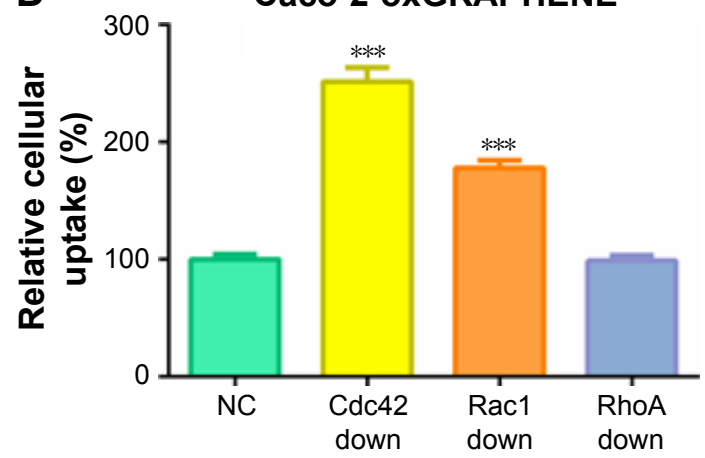

Figure 6 (Continued) 
E
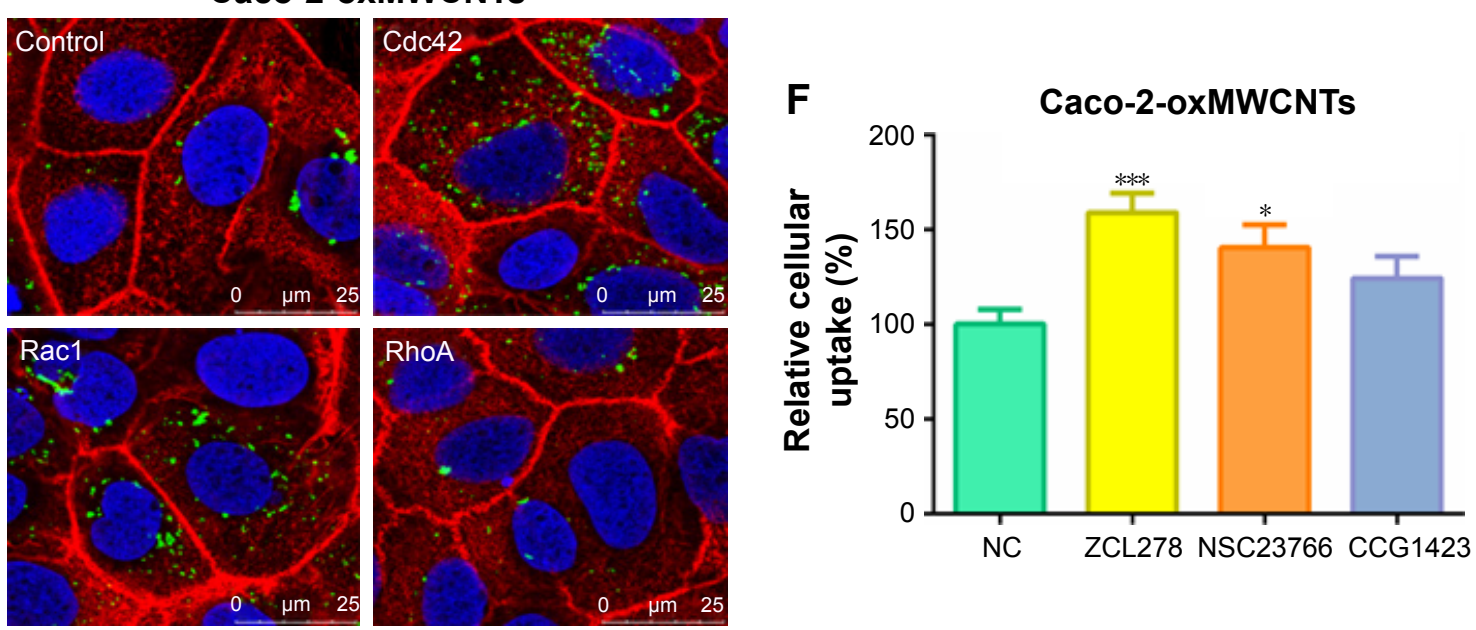

G
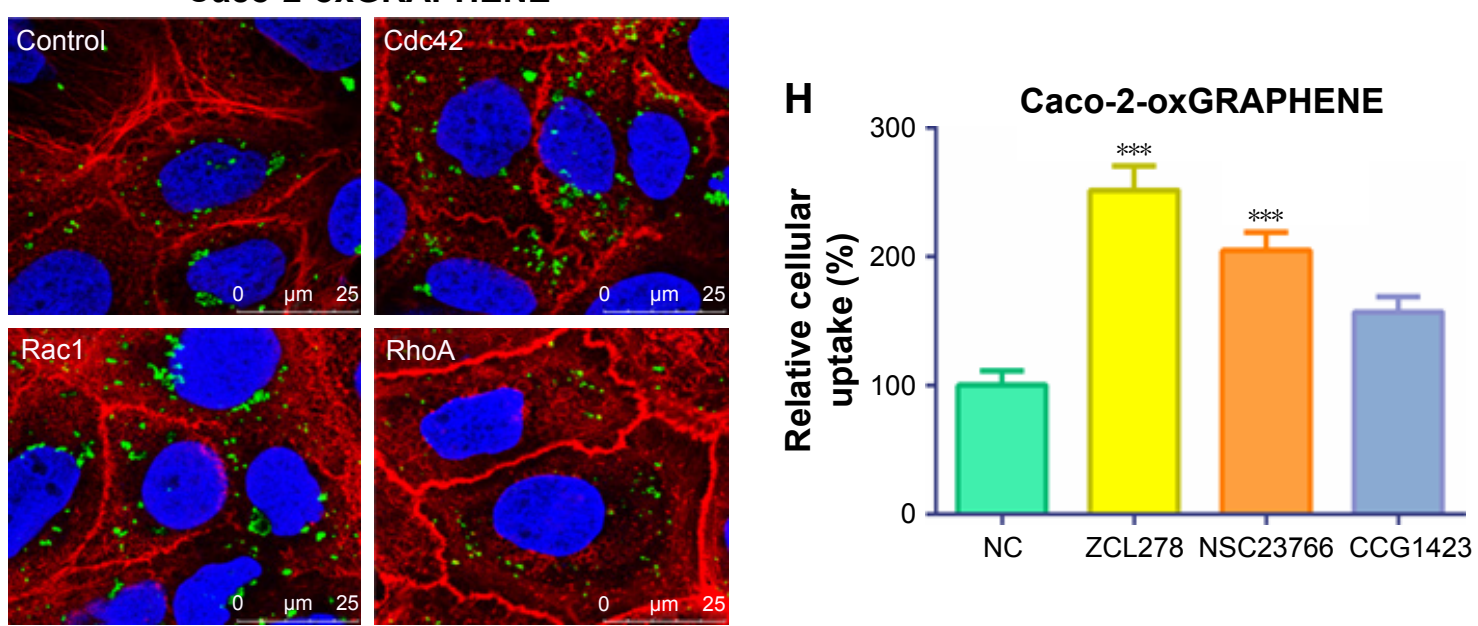

Figure 6 The endocytosis of oxMWCNTs and oxGRAPHENE in Caco-2 cells after down-regulation of Cdc42, Racl, and RhoA. (A-D) CLSM images of endocytosis and relative cellular uptake of oxMWCNTs or oxGRAPHENE in wild and Rho GTPase-silenced Caco-2 cells. (E-H) CLSM images of endocytosis and relative cellular uptake of oxMWCNTs or oxGRAPHENE in Caco- 2 cells after inactivation of Cdc42, Racl, and RhoA. Data were expressed as mean $\pm \mathrm{SE}$, $\mathrm{n}$ (indicates different cells) $\geq 30$ ( $* P<0.05$; $* * * P<0.001)$.

Abbreviations: MWCNTs, multi-walled carbon nanotubes; CLSM, confocal laser scanning microscopy; NC, negative control.

dynasore, filipin, genistein, chlorpromazine, cytochalasin D, and EIPA were used to block specific endocytic pathways. Under designated concentration, these inhibitors had no cytotoxicity (Figure 7).

As shown in Figure 7C and E, the intracellular amount of oxMWCNTs was reduced in both A549 cells and Caco- 2 cells when incubated with Dynasore, chlorpromazine. It is known that dynasore could inhibit dynamin and then affect the clathrin-mediated endocytosis and lipid raft/caveolin-mediated endocytosis, while chlorpromazine could inhibit clathrinmediated endocytosis. So, the cellular uptake of oxMWCNTs was mainly mediated by clathrin in both cell lines. OxGRAPHENE was affected by dynasore, filipin, genistein, and Cytochalasin D but not chlorpromazine (Figure 7D and F). Filipin was an inhibitor of lipid raft/caveolin-mediated endocytosis and genistein was reported to protenin-tyrosine kinase (PTK). Cytochalasin D is a cell-permeable and potent inhibitor of actin polymerization. So, the cellular uptake of oxGRAPHENE was mainly mediated by caveolin with participation of actin in both cell lines.

\section{The intracellular distribution of oxMWCNTs and oxGRAPHENE}

To observe the intracellular distribution of carbon nanomaterials, TEM analysis was performed. It was found that oxMWCNTs and oxGRAPHENE were transported to lysosomes and accumulated in lysosomes after entering A549 cells and Caco-2 cells (Figure 8). However, neither of the two materials were observed in mitochondria, Golgi complex, or endoplasmic reticulum in A549 or Caco-2 cells. 
A
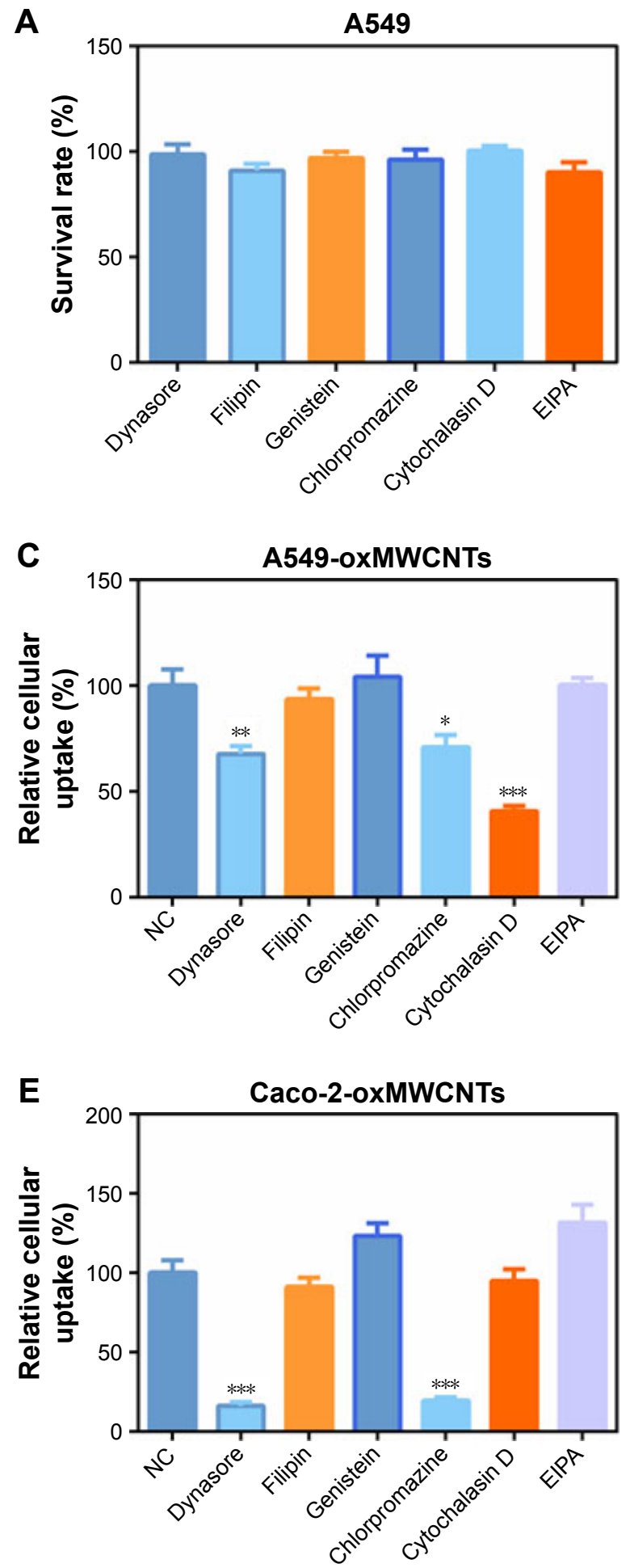

B

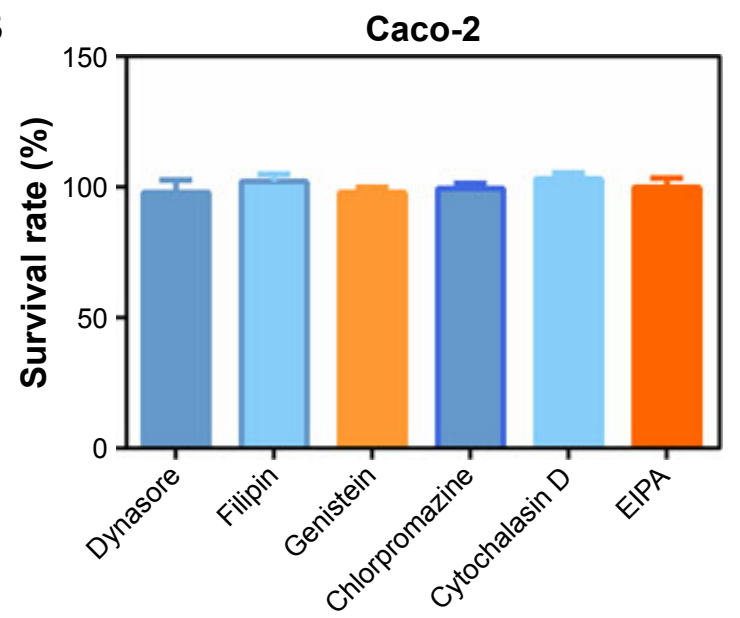

D

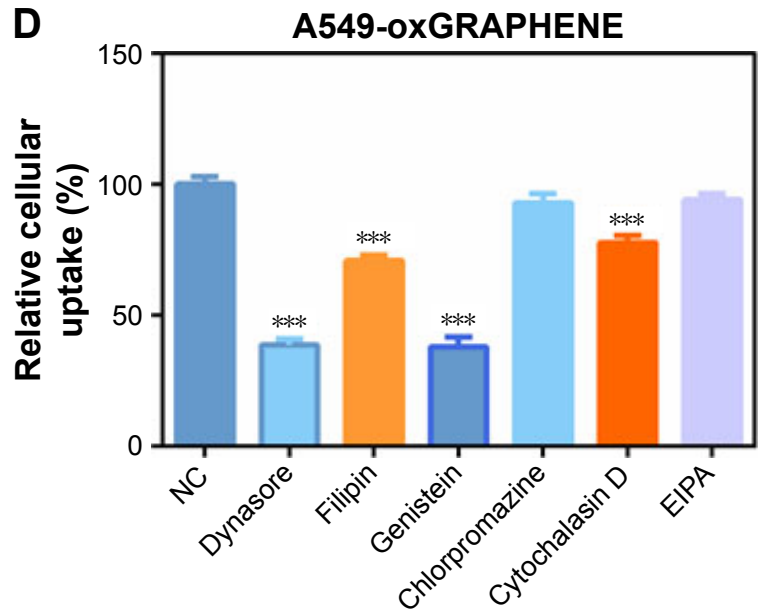

$\mathbf{F}$

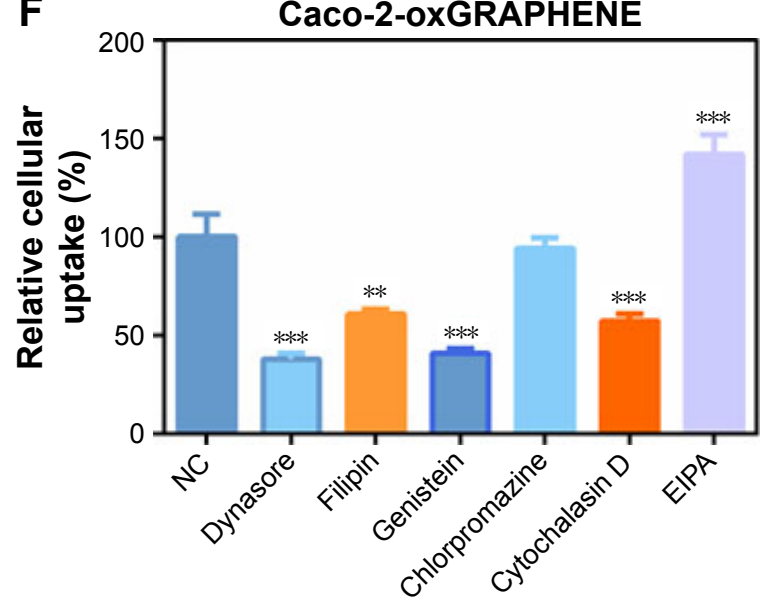

Figure 7 The viability of A549 cells and Caco-2 cells treated with inhibitors (A, B). The designated concentration of inhibitors showed no significant cytotoxicity in the two cell lines. The relative intracellular amount of oxMWCNTs in A549 cells (C), oxGRAPHENE in A549 cells (D), oxMWCNTs in Caco-2 cells (E), and oxGRAPHENE in Caco-2 cells (F) after blocking certain endocytic pathways. Data were expressed as mean $\pm \mathrm{SE}, \mathrm{n} \geq 30(* \mathrm{P}<0.05 ; * * P<0.01 ; * * * P<0.001)$.

Abbreviations: MWCNTs, multi-walled carbon nanotubes; NC, negative control.

\section{Conclusion}

The endocytosis and intracellular trafficking of nanomaterials have a major impact on their biological safety and function. Current studies explored these processes mainly through changing the physicochemical characterization of the nanomaterials. However, strategies for regulating the related intracellular signaling proteins are rarely exploited. Here, we tried to regulate the expression of three Rho GTPases, 
A
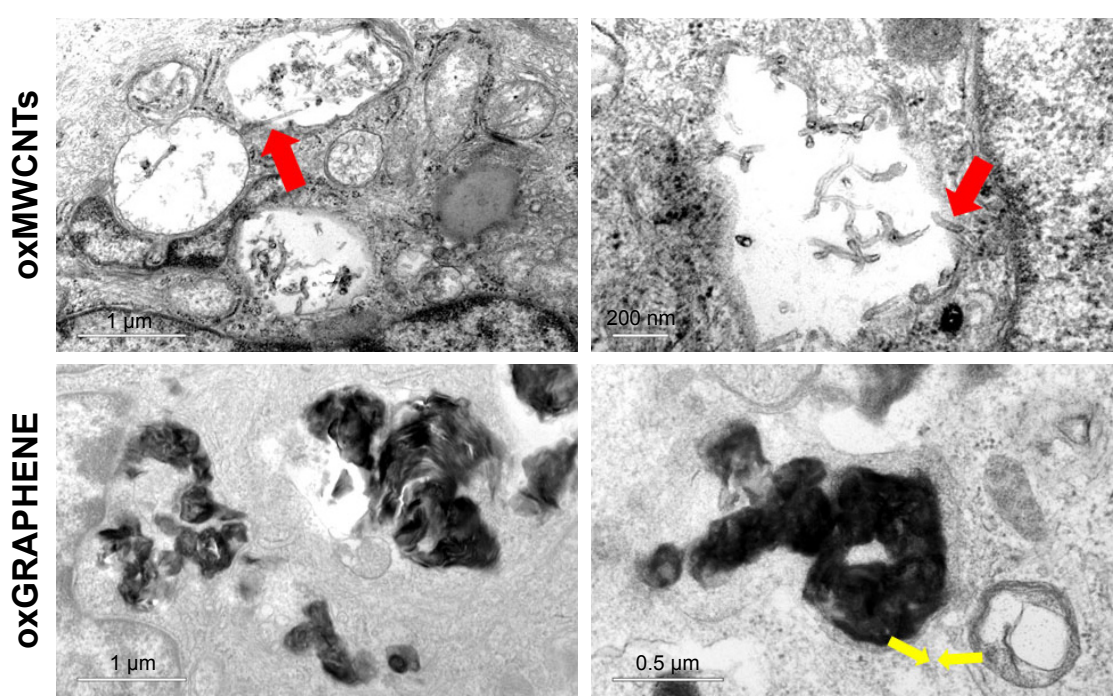

B
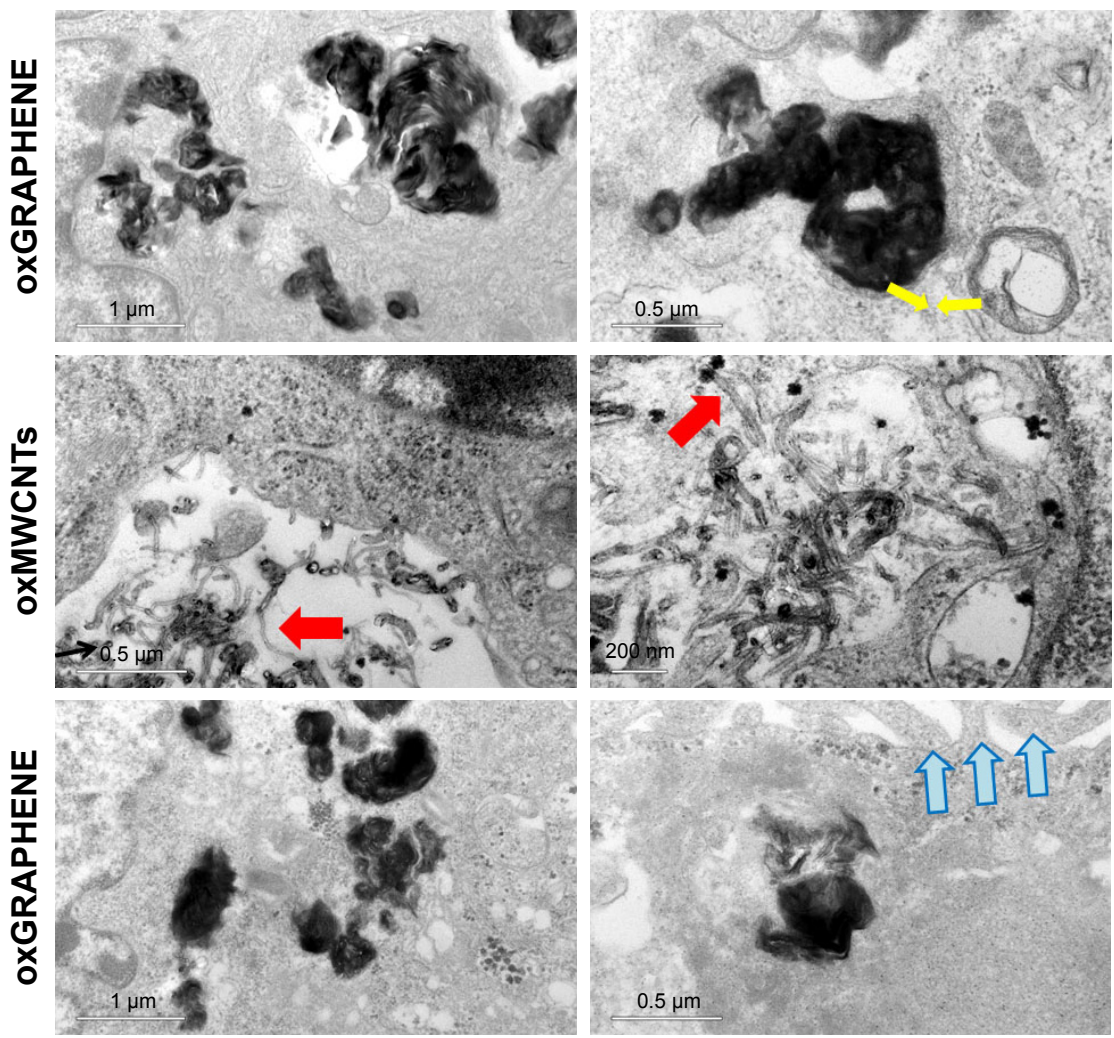

Figure 8 TEM images of oxMWCNTs and oxGRAPHENE in A549 cells (A) and Caco-2 cells (B). The red arrows refer to the oxMWCNTs penetrating the lysosomal membrane of A549 cells and Caco-2 cells. Yellow arrows refer to the movement direction of vesicles. Blue arrows refer to the microvilli structures of Caco-2 cells. Abbreviations: TEM, transmission electron microscopy; MWCNTs, multi-walled carbon nanotubes.

Cdc42, Rac1, and RhoA, and investigate their effects on internalization of oxMWCNTs and oxGRAPHENE in A549 and Caco-2 cells.

Consequently, it was found that three members of the Rho GTPase family participated in the process of cell uptake of nanomaterials with different shapes in a discriminative manner. Specifically, Cdc42 and Rac1 were found to play a role in the endocytosis of oxMWCNTs, while all three members (Cdc42, Rac1, and RhoA) were involved in the cell internalization of oxGRAPHENE. Cellular uptake of oxMWCNTs was mainly mediated by clathrin and that of oxGRAPHENE mostly by caveolin. Dynamin participated in the regulation of endocytosis of both nanomaterials in both cell lines (Figure 9). It was worth noting that the internalization changes caused by protein-molecule regulation also depended on the cell type. Namely, the silencing of Rho GTPases induced an increase in endocytosis of carbon nanomaterials in Caco- 2 cells but triggered a decreased uptake in A549 cells.

Our research focuses on evaluating the different mechanisms of endocytosis caused by nanomaterials based on different morphologies. The various structural characteristics of nanocarbon materials themselves will lead to diverse cellular uptakes. In addition to the traditional endocytosis, our research also focuses on the effect of GTPases.

The endocytosis of nanoparticles was affected by morphology, structure, size, composition, shape, structure, and so on. ${ }^{26-28}$ Therefore, the discovery of nanocarbon might not necessarily correlate with all nanomaterials. However, some studies were consistent with our research, eg, rod-like 


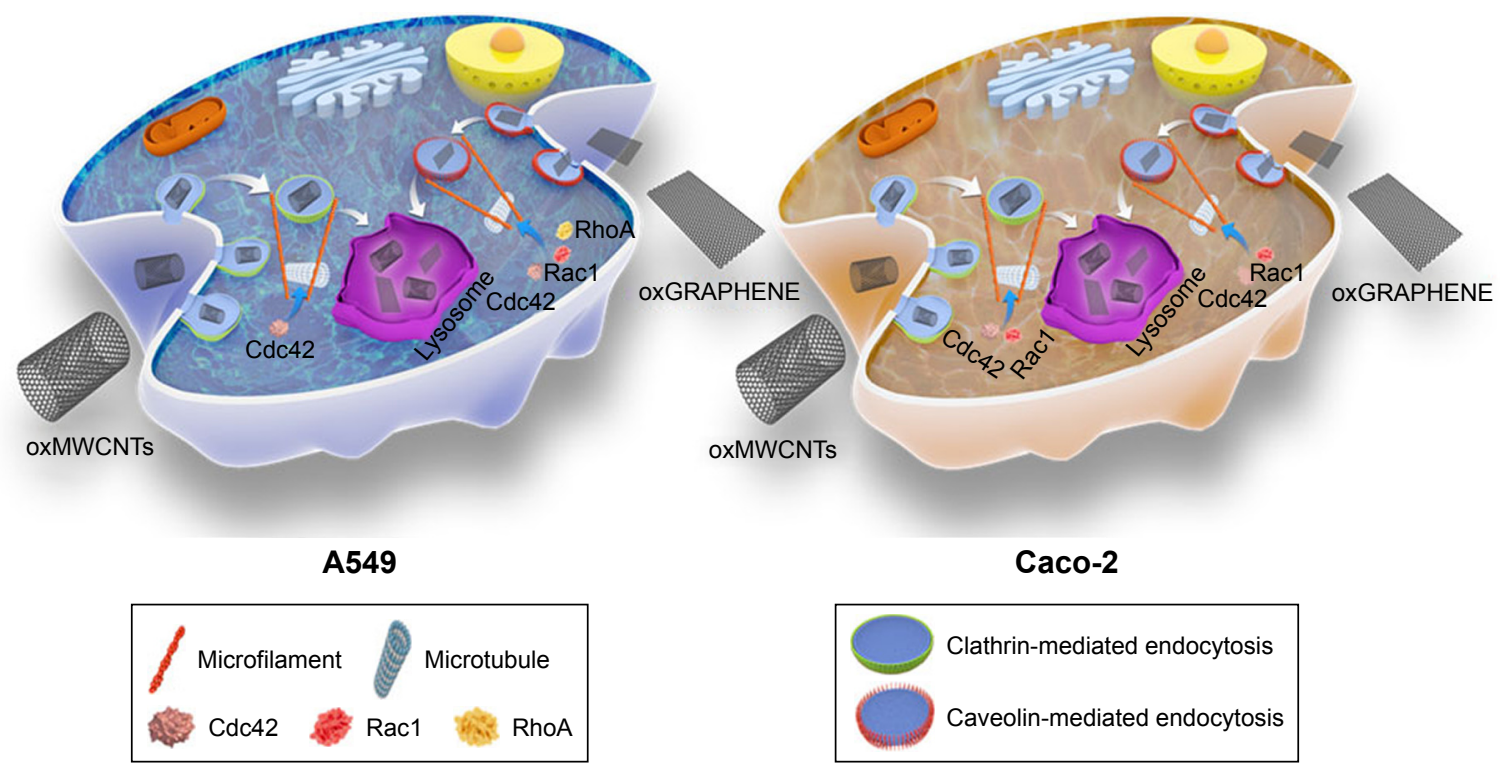

Figure 9 A schematic representation of oxMWCNTs and oxGRAPHENE endocytic pathways in A549 and Caco-2 cells. Abbreviation: MWCNTs, multi-walled carbon nanotubes.

materials were associated with clathrin-mediated endocytosis, and lamellar-like materials were related to caveolinmediated endocytosis. ${ }^{29-31}$

Meanwhile, this article considered the effects of GTPases on nanocarbon materials with different morphologies. Research has verified that the rod-like mesoporous silica nanoparticles with intermediary aspect ratio instead of spherical or other ratios, could induce activation of small GTP-binding proteins (eg, Rac1, CDC42), which assemble the actin cytoskeleton and filopodia formation. ${ }^{32}$ Therefore, the differences in materials' morphology could lead to different types of GTPases being involved.

The "model" can be used to confirm other nanomaterials and the finding of this study can be used for comparing the morphology of the same materials. At present, we are focusing on the use of other materials for follow-up studies, such as SWCNH or other types of materials like gold nanoparticles, gold nanorods, etc. Our aim is to establish whether this theory can provide more extensive guidance for further studies.

Generally, these findings might provide new insights for the design of nano-sized drug delivery systems and the understanding of their interactions with different cells.

\section{Acknowledgments}

The authors thank associate Prof Lan Yuan for technical assistance with CLSM. The work was supported by the National Natural Science Foundation of China (81690264), the National Basic Research Program of China (2015CB932100,
2017YFA0205600), and the Innovation Team of the Ministry of Education (BMU20110263).

\section{Disclosure}

The authors report no conflicts of interest in this work.

\section{References}

1. Nagamune T. Biomolecular engineering for nanobio/bionanotechnology. Nano Converg. 2017;4(1):9.

2. Salatin S, Maleki Dizaj S, Yari Khosroushahi A. Effect of the surface modification, size, and shape on cellular uptake of nanoparticles Cell Biol Int. 2015;39(8):881-890.

3. Huang X, Teng X, Chen D, Tang F, He J. The effect of the shape of mesoporous silica nanoparticles on cellular uptake and cell function. Biomaterials. 2010;31(3):438-448.

4. Wang X, Lin L, Liu R, et al. Anisotropy in shape and ligand-conjugation of hybrid nanoparticulates manipulates the mode of bio-nano interaction and its outcome. Adv Funct Mater. 2017;27(31):1700406.

5. Anitei M, Hoflack B. Bridging membrane and cytoskeleton dynamics in the secretory and endocytic pathways. Nat Cell Biol. 2012;14(1): 11-19.

6. Machacek M, Hodgson L, Welch C, et al. Coordination of Rho GTPase activities during cell protrusion. Nature. 2009;461(7260):99-103.

7. Lee S, Craig BT, Romain CV, Qiao J, Chung DH. Silencing of CDC42 inhibits neuroblastoma cell proliferation and transformation. Cancer Lett. 2014;355(2):210-216.

8. Lamaze C, Chuang TH, Terlecky LJ, Bokoch GM, Schmid SL. Regulation of receptor-mediated endocytosis by Rho and Rac. Nature. 1996; 382(6587):177-179.

9. Oprea TI, Sklar LA, Agola JO, et al. Novel activities of select NSAID R-enantiomers against Rac1 and Cdc42 GTPases. PLoS One. 2015; 10(11): 0142182.

10. Martin K, Reimann A, Fritz RD, et al. Spatio-temporal co-ordination of RhoA, Rac1 and Cdc42 activation during prototypical edge protrusion and retraction dynamics. Sci Rep. 2016;6:21901.

11. Datsyuk V, Kalyva M, Papagelis K, et al. Chemical oxidation of multiwalled carbon nanotubes. Carbon. 2008;46(6):833-840. 
12. Becerril HA, Mao J, Liu Z, et al. Evaluation of solution-processed reduced graphene oxide films as transparent conductors. ACS Nano. 2008;2(3):463-470.

13. Rosca ID, Watari F, Uo M, Akasaka T. Oxidation of multiwalled carbon nanotubes by nitric acid. Carbon. 2005;43(15):3124-3131.

14. Shieh YT, Liu GL, Wu HH, Lee CC. Effects of polarity and $\mathrm{pH}$ on the solubility of acid-treated carbon nanotubes in different media. Carbon. 2007;45(9):1880-1890.

15. Kurien BT, Scofield RH. Western blotting. Methods. 2006;38(4): 283-293.

16. Hornung V, Bauernfeind F, Halle A, et al. Silica crystals and aluminum salts activate the NALP3 inflammasome through phagosomal destabilization. Nat Immunol. 2008;9(8):847-856.

17. Koivusalo M, Welch C, Hayashi H, et al. Amiloride inhibits macropinocytosis by lowering submembranous $\mathrm{pH}$ and preventing $\mathrm{Rac1}$ and Cdc42 signaling. J Cell Biol. 2010;188(4):547-563.

18. Wu M, Yuan F. Membrane binding of plasmid DNA and endocytic pathways are involved in electrotransfection of mammalian cells. PLoS One. 2011;6(6):e20923.

19. Yan GR, Zou FY, Dang BL, et al. Genistein-induced mitotic arrest of gastric cancer cells by downregulating KIF20A, a proteomics study. Proteomics. 2012;12(14):2391-2399.

20. Gitrowski C, Al-Jubory AR, Handy RD. Uptake of different crystal structures of $\mathrm{TiO} 2$ nanoparticles by Caco- 2 intestinal cells. Toxicol Lett. 2014;226(3):264-276.

21. Shoji K, Ohashi K, Sampei K, Oikawa M, Mizuno K. Cytochalasin D acts as an inhibitor of the actin-cofilin interaction. Biochem Biophys Res Commun. 2012;424(1):52-57.

22. Buschiazzo J, Bonini IC, Alonso TS. Inhibition of Bufo arenarum oocyte maturation induced by cholesterol depletion by methyl- $\beta$-cyclodextrin. Role of low-density caveolae-like membranes. Biochim Biophys Acta. 2008;1778(6):1398-1406.
23. Li M, Boggs M, Beebe TP, Huang C. Oxidation of single-walled carbon nanotubes in dilute aqueous solutions by ozone as affected by ultrasound. Carbon. 2008;46(3):466-475.

24. Popoff MR, Geny B. Multifaceted role of Rho, Rac, Cdc42 and Ras in intercellular junctions, lessons from toxins. Biochim Biophys Acta. 2009; 1788(4):797-812.

25. Vandenbroucke E, Mehta D, Minshall R, Malik AB. Regulation of endothelial junctional permeability. Ann N Y Acad Sci. 2008;1123(1): 134-145.

26. Zhang S, Gao H, Bao G. Physical principles of nanoparticle cellular endocytosis. ACS Nano. 2015;9(9):8655-8671.

27. Oh N, Park JH. Endocytosis and exocytosis of nanoparticles in mammalian cells. Int J Nanomedicine. 2014;9 Suppl 1:51-63.

28. Salatin S, Yari Khosroushahi A. Overviews on the cellular uptake mechanism of polysaccharide colloidal nanoparticles. J Cell Mol Med. 2017; 21(9):1668-1686.

29. Boylan NJ, Kim AJ, Suk JS, et al. Enhancement of airway gene transfer by DNA nanoparticles using a $\mathrm{pH}$-responsive block copolymer of polyethylene glycol and poly-L-lysine. Biomaterials. 2012;33(7): 2361-2371.

30. Kim AJ, Woodworth GF, Boylan NJ, Suk JS, Hanes J. Highly compacted $\mathrm{pH}$-responsive DNA nanoparticles mediate transgene silencing in experimental glioma. J Mater Chem B. 2014;2(46):8165-8173.

31. Wang XY, Lei R, Huang HD, et al. The permeability and transport mechanism of graphene quantum dots (GQDs) across the biological barrier. Nanoscale. 2015;7(5):2034-2041.

32. Meng H, Yang S, Li Z, et al. Aspect ratio determines the quantity of mesoporous silica nanoparticle uptake by a small GTPase-dependent macropinocytosis mechanism. ACS Nano. 2011;5(6):4434-4447.
International Journal of Nanomedicine

\section{Publish your work in this journal}

The International Journal of Nanomedicine is an international, peerreviewed journal focusing on the application of nanotechnology in diagnostics, therapeutics, and drug delivery systems throughout the biomedical field. This journal is indexed on PubMed Central, MedLine, CAS, SciSearch $®$, Current Contents ${ }^{\circledR} /$ Clinical Medicine,

\section{Dovepress}

Journal Citation Reports/Science Edition, EMBase, Scopus and the Elsevier Bibliographic databases. The manuscript management system is completely online and includes a very quick and fair peer-review system, which is all easy to use. Visit http://www.dovepress.com/ testimonials.php to read real quotes from published authors. 